\title{
Pengaruh Motif Mengakses Akun Video dalam Aplikasi Chatting terhadap Kepuasan Khalayak (Survei terhadap Generasi Milenial yang Menggunakan LINE TODAY)
}

\author{
Parousia, Riris Loisa \\ itsparousia@gmail.com,ririsl@fikom.untar.ac.id
}

Fakultas Ilmu Komunikasi Universitas Tarumanagara

\begin{abstract}
Humans who continue to communicate with other humans cause the spread and acceptance of information increasingly consciously or unconsciously. This also causes a lot of renewal in various fields of life, including information technology. Now, information are more easily and quickly accessed through various existing media, including through new media and social media. This research purposed to know the effect of motives for accessing video accounts in chat applications towards audience satisfaction. This research uses social media theory, new media, and uses and gratification theory. The approach used is quantitative. The sampling technique used was non probability sampling, purposive sampling with a sample of 100 respondents who are millennials who access video accounts in a chat application (LINE TODAY). Data collected by distributed Google Forms questionnaires consisting of 18 indicators. The final result obtained are closeness between the two variables included in the high criteria. And there is an influence between the two variables whose direction is said to be positive.
\end{abstract}

Keywords: audience satisfaction, motives, video accounts.

\begin{abstract}
Abstrak
Manusia yang terus menerus melakukan komunikasi dengan manusia lain menyebabkan persebaran dan penerimaan terhadap informasi semakin meningkat secara sadar maupun tidak disadari. Ini juga menyebabkan banyak pembaharuan di berbagai bidang kehidupan, tak terkecuali teknologi informasi. Kini, kemudahan dan cepat nya akses informasi melalui banyak media yang ada, termasuk melalui media baru dan media sosial. Penelitian bertujuan untuk mengetahui pengaruh motif mengakses akun video dalam aplikasi chatting terhadap kepuasan khalayak. Pendekatan yang digunakan adalah kuantitatif. Penelitian ini menggunakan teori sosial media, media baru, penggunaan dan kepuasan media. Sampling yang digunakan adalah teknik non probabilitas, teknik purposive sampling dengan sampel sebanyak 100 responden merupakan generasi milenial yang mengakses akun video dalam aplikasi chatting (LINE TODAY). Pengumpulan data didasarkan hasil jawaban dari kuesioner Google Forms yang terdiri dari 18 indikator. Hasil akhir yang diperoleh adalah keeratan antara dua variabel termasuk dalam kriteria tinggi. Serta terdapat pengaruh antara kedua variabel yang arahnya dikatakan positif.
\end{abstract}

Kata Kunci: akun video, kepuasan khalayak, Motif. 


\section{Pendahuluan}

Sebagai makhluk sosial, manusia selalu melakukan komunikasi antara satu dengan yang lain. Manusia yang selalu melakukan komunikasi dengan manusia lain menyebabkan persebaran dan penerimaan terhadap informasi semakin meningkat secara sadar maupun tidak disadari. Ini menyebabkan banyak pembaharuan di berbagai bidang kehidupan, tak terkecuali teknologi informasi, dan kehadiran media baru, termasuk media sosial. Menurut Azeharie, Suzy \& Kusuma, Octavia (2014) Perkembangan teknologi internet dan mobile phone diiringi pula dengan pertumbuhan media sosial yang semakin pesat. Dengan munculnya beragam media sosial maka para pengguna internet semakin dimudahkan untuk saling berkomunikasi.

Gambar 1. Medsos yang paling banyak digunakan masyarakat Indonesia

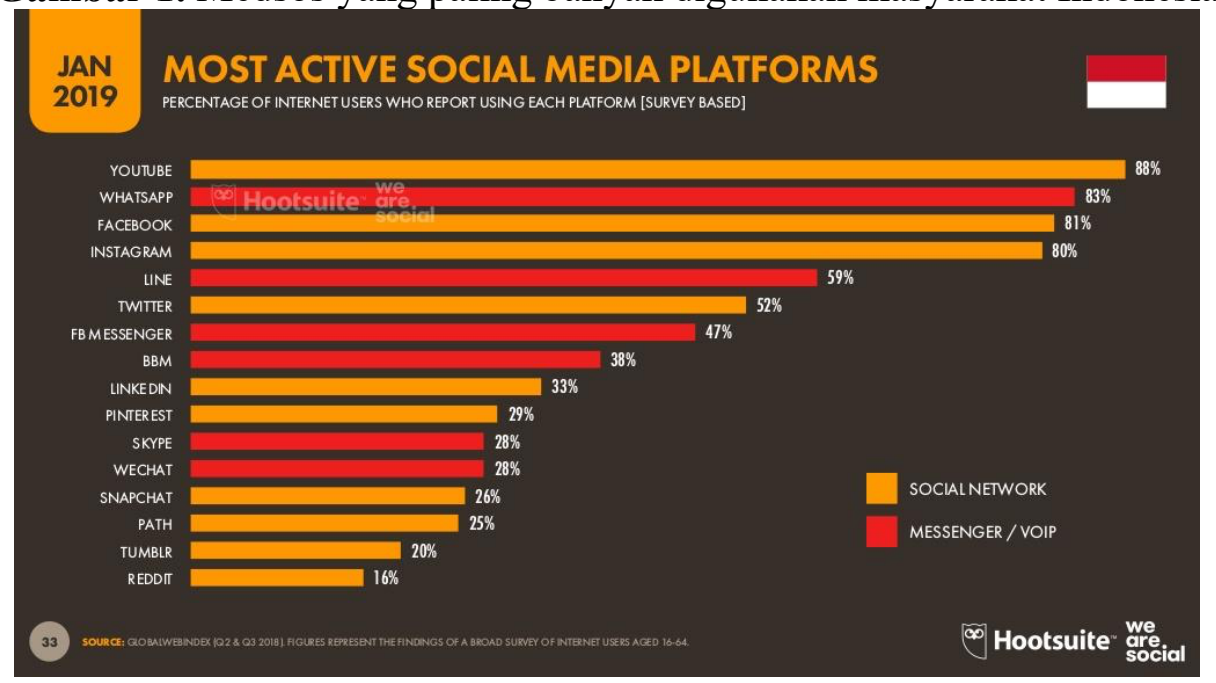

Sumber: datareportal.com

Hari ini, informasi kian mudah diakses melalui banyak macam media, termasuk melalui media sosial. Hal ini diperkuat oleh survei yang dilakukan oleh We Are Social, bahwa dari banyak media sosial yang ada, YouTube adalah salah satu yang paling sering digunakan. Ini menunjukkan bahwa penduduk Indonesia gemar mengonsumsi konten dalam bentuk audio-visual.

Selain YouTube sebagai media sosial yang digemari penduduk Indonesia, ada pula salah satu perusahaan aplikasi instant messaging, yakni LINE yang berinovasi. Aplikasi LINE terbilang sangat akrab, bahkan merupakan konsumsi sehari-hari anak muda, khususnya generasi milenial. Revie Sylviana (2018), sebagai Strategic Partnership Director Line Indonesia dalam sebuah artikel Kumparan.com berujar bahwa nilai plus LINE terletak pada stiker, tema untuk aplikasi, video call grup, live streaming film dan video, hingga game, layanan baca berita seperti LINE TODAY, lowongan kerja LINE Jobs, forum bernama LINE Square, dan sebagainya. Selain itu ia juga mengungkapkan, saat ini pengguna LINE di Tanah Air mencapai 90 juta.

Selain berfungsi untuk berkirim pesan instan, LINE juga meluncurkan fitur yang bernama LINE TODAY pada tahun 2016 lalu. LINE TODAY adalah sebuah fitur yang ditambahkan oleh aplikasi Naver untuk mengakses berita. 
Gambar 2. Akun video dalam aplikasi chatting

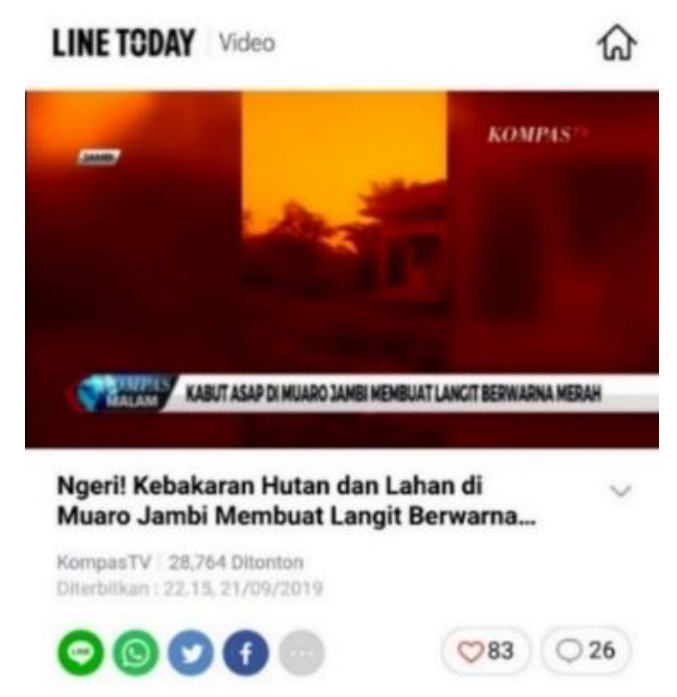

Sumber: Halaman LINE TODAY (2019)

LINE TODAY juga menghadirkan berita dalam bentuk video (News Video). News Video yang ditayangkan di fitur LINE TODAY adalah berasal dari berbagai YouTube channel. LINE TODAY resmi menjadi aplikasi sendiri bagi iOS dan Android sejak juni 2018 lalu, namun fitur LINE TODAY di dalam aplikasi chatting tetap ada dan dapat diakses. Oleh karena besarnya angka penggunaan media YouTube dan adanya kemudahan untuk mengakses informasi melalui fitur LINE TODAY yang berada di dalam aplikasi chatting, peneliti ingin melakukan penelitian yang berjudul "Pengaruh Motif Mengakses Akun Video dalam Aplikasi Chatting terhadap Kepuasan Khalayak".

Agar dapat fokus pada permasalahan yang akan diteliti, maka perumusan masalah untuk penelitian ini adalah sebagai berikut: Apakah motif mengakses akun video dalam aplikasi chatting berpengaruh secara signifikan terhadap kepuasan khalayak?.

Penelitian bertujuan agar masalah yang ingin diteliti dapat terjawab, maka dari itu, penelitian ini memiliki tujuan untuk mengetahui motif mengakses akun video dalam aplikasi chatting berpengaruh secara signifikan atau tidak terhadap kepuasan khalayak.

Arti hipotesis menurut para ahli adalah perkiraan hubungan antara dua variabel atau lebih. Dapat disimpulkan, hipotesis adalah perkiraan (dugaan) sementara atau jawaban yang harus diuji validitasnya. (Siregar, 2014).

Berdasarkan isi rumusannya hipotesis dapat dibedakan menjadi dua bentuk, yaitu:

a) Hipotesis alternatif $(\mathrm{Ha})$

Hipotesis yang menyatakan pembenaran dari suatu fenomena.

b) Hipotesis Nol (Ho)

Hipotesis yang menyatakan kesalahan dari suatu fenomena. (Siregar, 2014).

Berdasarkan definisi di atas mengenai hipotesis, maka peneliti menetapkan hipotesis penelitian sebagai berikut: Ha: Ada pengaruh signifikan motif mengakses akun video dalam aplikasi chatting terhadap kepuasan khalayak. Ho: Tidak ada 
pengaruh signifikan motif mengakses akun video dalam aplikasi chatting terhadap kepuasan khalayak.

\section{Metode Penelitian}

Penelitian ini menggunakan pendekatan kuantitatif. Penelitian ini dilakukan dengan mengumpulkan data berupa angka, atau data berupa kata-kata atau kalimat yang dikonversi menjadi data yang berbentuk angka.

Peneliti menggunakan survei sebagai metode pada penelitian ini. Menurut Kriyantono (2010) tujuan survei adalah mendapatkan informasi mengenai sejumlah responden yang dapat mewakili populasi. Menurut Sujarweni (2014) Populasi adalah seluruh obyek atau subyek yang mempunyai karakteristik dan kualitas tertentu yang ditetapkan oleh peneliti untuk diteliti dan kemudian ditarik kesimpulannya.

Populasi dalam penelitian ini adalah individu-individu yang termasuk dalam kategori milenial yang mengakses (menonton) akun video dalam aplikasi chatting (yakni LINE TODAY) yang jumlah nya tidak diketahui.

Menurut Martono (2016) Sampel merupakan bagian dari populasi yang memiliki keadaan tertentu, atau sebagian anggota yang dipilih dengan menggunakan prosedur tertentu sehingga diharapkan dapat mewakili populasi. Sampel perlu digunakan agar memudahkan peneliti untuk meneliti dalam jumlah yang lebih sedikit dibanding menggunakan populasi dengan jumlah besar. Dengan adanya sampel, penelitian dapat dilaksanakan lebih efisien, peneliti juga dapat lebih cermat dalam melakukan pengumpulan data.

Pada penelitian ini, peneliti menetapkan 100 responden sebagai jumlah sampel. Pengumpulan data dilakukan dengan kuesioner. Pengumpulan data merupakan langkah yang amat penting, karena data yang akan dikumpulkan akan diperlukan untuk memecahkan masalah yang ingin diteliti atau untuk menguji hipotesis (dugaan) yang telah dirumuskan. (Siregar, 2014).

Teknik analisis data yang diterapkan pada data yang didapatkan dari kuesioner yang telah diisi oleh responden adalah analisis koefisien korelasi, analisis regresi linear sederhana, dan uji koefisien determinasi. Menurut Nisfiannoor (2013) analisis koefisien korelasi diperlukan untuk mengukur keeratan variabel, yaitu variabel X (motif) dan variabel Y (kepuasan khalayak). Analisis regresi sederhana ditujukan untuk mencari bentuk hubungan dua variabel atau lebih dalam bentuk fungsi atau persamaan. (Kriyantono, 2010). Terakhir, uji koefisien determinasi, menurut Ghozali (2016) tujuan koefisien determinasi $\left(\mathrm{R}^{2}\right)$ adalah untuk mengukur kemampuan model dalam menerangkan variasi variabel independen. Nilai koefisien determinasi adalah antara nol dan satu, nilai $\mathrm{R}^{2}$ yang kecil berarti kemampuan variabel-variabel independen dalam menjelaskan variasi variabel dependen amat terbatas.

\section{Hasil Temuan dan Diskusi}

Tabel 1. Jenis Kelamin Responden

\begin{tabular}{|c|l|r|r|r|r|}
\hline \multicolumn{2}{|c|}{} & Frequency & Percent & $\begin{array}{c}\text { Valid } \\
\text { Percent }\end{array}$ & $\begin{array}{c}\text { Cumulative } \\
\text { Percent }\end{array}$ \\
\hline \multirow{2}{*}{ Valid } & LAKI-LAKI & 60 & 60.0 & 60.0 & 60.0 \\
\cline { 2 - 6 } & PEREMPUAN & 40 & 40.0 & 40.0 & 100.0 \\
\hline
\end{tabular}




$$
\begin{array}{|l|r|r|r|}
\text { Total } & 100 & 100.0 & 100.0 \\
\hline
\end{array}
$$

Sumber: Hasil olah data dengan program SPSS 25

Tabel 2. Usia

\begin{tabular}{|l|l|r|r|r|r|}
\hline \multicolumn{2}{|c|}{} & Frequency & Percent & $\begin{array}{c}\text { Valid } \\
\text { Percent }\end{array}$ & $\begin{array}{c}\text { Cumulative } \\
\text { Percent }\end{array}$ \\
\hline Valid & $\begin{array}{l}19-25 \\
\text { Tahun }\end{array}$ & 89 & 89.0 & 89.0 & 89.0 \\
\cline { 2 - 6 } & $\begin{array}{l}26-32 \\
\text { Tahun }\end{array}$ & 11 & 11.0 & 11.0 & 100.0 \\
\cline { 2 - 6 } & Total & 100 & 100.0 & 100.0 & \\
\hline
\end{tabular}

Sumber: Hasil olah data dengan program SPSS 25

Tabel 3. Dari mana Mengetahui

\begin{tabular}{|l|l|r|r|r|r|}
\hline \multicolumn{2}{|c|}{} & Frequency & Percent & $\begin{array}{c}\text { Valid } \\
\text { Percent }\end{array}$ & $\begin{array}{c}\text { Cumulative } \\
\text { Percent }\end{array}$ \\
\hline Valid & $\begin{array}{l}\text { APLIKASI } \\
\text { LINE }\end{array}$ & 92.0 & 92.0 & 92.0 \\
\cline { 2 - 6 } & TEMAN & 2 & 2.0 & 2.0 & 94.0 \\
\cline { 2 - 6 } & $\begin{array}{l}\text { MEDIA } \\
\text { SOSIAL }\end{array}$ & 6 & 6.0 & 6.0 & 100.0 \\
\cline { 2 - 6 } & Total & 100 & 100.0 & 100.0 & \\
\hline
\end{tabular}

Sumber: Hasil olah data dengan program SPSS 25

Tabel 4. Motif Hiburan

\begin{tabular}{|l|l|r|r|r|r|}
\hline \multicolumn{2}{|c|}{} & Frequency & Percent & $\begin{array}{c}\text { Valid } \\
\text { Percent }\end{array}$ & $\begin{array}{c}\text { Cumulative } \\
\text { Percent }\end{array}$ \\
\hline \multirow{7}{*}{ Valid } & $\begin{array}{l}\text { SANGAT TIDAK } \\
\text { SETUJU }\end{array}$ & 8 & 8.0 & 8.0 & 8.0 \\
\cline { 2 - 6 } & & & & 23.0 \\
\cline { 2 - 6 } & SIDAK SETUJU & 15 & 15.0 & 15.0 & 73.0 \\
\cline { 2 - 6 } & SETUJU & 50 & 50.0 & 50.0 & 100.0 \\
\cline { 2 - 6 } & SANGAT SETUJU & 27 & 27.0 & 27.0 & \\
\cline { 2 - 6 } & Total & 100 & 100.0 & 100.0 & \\
\hline
\end{tabular}

Sumber: Hasil olah data dengan program SPSS 25

Tabel 5. Kepuasan Informasi

\begin{tabular}{|c|c|c|c|c|c|}
\hline \multicolumn{2}{|c|}{} & Frequency & Percent & Valid Percent & $\begin{array}{c}\text { Cumulative } \\
\text { Percent }\end{array}$ \\
\hline Valid & $\begin{array}{c}\text { SANGAT TIDAK } \\
\text { SETUJU }\end{array}$ & 1 & 1.0 & 1.0 & 1.0 \\
\cline { 2 - 6 } & TIDAK SETUJU & 8 & 8.0 & 8.0 & 9.0 \\
\cline { 2 - 6 } & SETUJU & 57 & 57.0 & 57.0 & 66.0 \\
\cline { 2 - 6 } & SANGAT SETUJU & 34 & 34.0 & 34.0 & 100.0 \\
\cline { 2 - 6 } & Total & 100 & 100.0 & 100.0 & \\
\hline
\end{tabular}

Sumber: Hasil olah data dengan program SPSS 25 
Dari penelitian yang dilakukan diperoleh data bahwa khalayak yang dominan mengakses atau menonton akun video adalah berjenis kelamin laki-laki sebanyak 60 responden, fitur LINE TODAY adalah mayoritas digunakan oleh mereka yang berusia 19-25 tahun, yakni sebanyak 89 responden, dan responden mengetahui fitur LINE TODAY sebanyak 92 responden dari aplikasi LINE itu sendiri. Indikator yang memiliki perolehan nilai tertinggi atau berpengaruh pada variabel $\mathrm{X}$ (motive) adalah motif hiburan yaitu "Ingin memperoleh hiburan dan merasa senang". Indikator yang memiliki perolehan nilai tertinggi atau berpengaruh pada variabel $\mathrm{Y}$ (kepuasan) adalah kepuasan informasi yaitu "Mengetahui opini publik mengenai peristiwa yang sedang terjadi". Didapat hasil berupa angka koefisien sebesar 0,749 dan dengan demikian dikatakan bahwa keeratan antara dua variabel adalah termasuk dalam kriteria tinggi karena koefisien dengan rentang 0.6-0.79 adalah termasuk dalam kriteria tinggi. Dari hasil uji koefisien determinasi dapat disimpulkan bahwa variabel $\mathrm{X}$ berpengaruh terhadap variabel $\mathrm{Y}$ sebanyak 56,2 \% sementara 43,8 sisanya dijelaskan oleh variabel-variabel lain.

\section{Simpulan}

Motif mengakses akun video dalam aplikasi chatting berpengaruh secara signifikan terhadap kepuasan khalayak berdasarkan uji signifikansi. Pernyataan $\mathrm{Ha}$ pada "Ada pengaruh signifikan motif mengakses akun video dalam aplikasi chatting terhadap kepuasan khalayak" adalah diterima dan Ho ditolak. Survei yang telah dilakukan terhadap responden yang merupakan pengguna LINE TODAY melalui Google Forms, didapatkan hasil bahwa kepuasan yang diperoleh khalayak dipengaruhi sebesar 56,2 \% oleh motif mengakses akun video itu sendiri, sementara sisanya dijelaskan oleh variabel-variabel lainnya.

Dari hasil uji regresi linear diperoleh angka 0,669 yang bernilai positif, selain itu nilai signifikansi yang didapat adalah $<0,05$. Dengan demikian dapat dikatakan bahwa pernyataan Ha "Ada pengaruh motif mengakses akun video dalam aplikasi chatting terhadap kepuasan khalayak" adalah diterima dan Ho ditolak.

\section{Ucapan Terima Kasih}

Pertama-tama peneliti mengucapkan terima kasih kepada Tuhan YME atas terselesaikannya jurnal ini dengan baik. Selanjutnya, peneliti berterima kasih sebesar-besarnya kepada keluarga. Peneliti juga sangat berterima kasih sebesarbesarnya kepada semua pihak yang bersedia mengisi kuesioner ini karena tanpa kalian, tidak akan didapatkan data yang dibutuhkan untuk penelitian ini. Terakhir, peneliti berterima kasih kepada seluruh pihak yang memberi dukungan juga bantuan hingga akhirnya penelitian ini selesai dengan baik.

\section{Daftar Pustaka}

Digital 2019: Indonesia - DataReportal - Global Digital Insights. (n.d.). Retrieved December 15, 2019, from https://datareportal.com/reports/digital-2019indonesia

Kriyantono, Rachmat. (2014). Teknik Praktis Riset Komunikasi. Jakarta: Kencana Prenada Media Group. 
Martono, Nanang. (2016). Metode penelitian kuantitatif: analisis isi dan analisis data sekunder (Ed. Revisi 2.). Jakarta: Rajawali Pers 2016.

Nisfiannoor, Muhammad. (2013). Pendekatan Statistika Modern: Aplikasi Dengan Software Dan E-Views. Jakarta: Penerbit Universitas Indonesia.

Pengguna LINE di Indonesia Capai 90 Juta, Didominasi Anak Muda kumparan.com. (n.d.). Retrieved November 16, 2019, from https://kumparan.com/kumparantech/pengguna-line-di-indonesia-capai-90juta-didominasi-anak-muda

Siregar, Sofyan. (2012). Statistika Deskriptif Untuk Penelitian. Jakarta: PT RajaGrafindo Persada.

Sujarweni, V.Wiratna. (2014). Metodologi Penelitian. Yogyakarta: PUSTAKA BARU PRESS.

Azeharie, Suzy dan Kusuma, Octavia. (2014). Analisis Penggunaan Twitter Sebagai Media Komunikasi Selebritis Di Jakarta. Jurnal Ilmu Komunikasi Vol.6, No2, 82-96. 